\title{
Power Control of a Variable Speed Wind Turbine Driving an DFIG
}

\author{
D.Aouzellag ${ }^{1}$, K.Ghedamsi ${ }^{1}$, E.M.Berkouk ${ }^{2}$ \\ (1) Electrical engineering Department, A.Mira University, Bejaïa, Algeria \\ e_mail: kghedamsi@yahoo.fr, e_mail: aouzellag@hotmail.com \\ (2) Control Process Laboratory, E.N.P, Algiers, Algeria \\ e_mail: emberkouk@yahoo.fr
}

\begin{abstract}
In this paper, a grid connected wind power generation scheme using a doubly fed induction generator ( DFIG) is studied. The aims of this paper are: The modelling and simulation of the operating in two quadrants (torque-speed ) of a DFIG, the analysis employs a stator flux vector control algorithm to control rotor current, the system enables optimal speed tracking for maximum energy capture from the wind and high performance active and reactive power regulation using the RST regulator.

The simulation calculations were achieved using MATLAB ${ }^{\circledR}$ SIMULINK $^{\circledR}$ package. Lastly, the obtained results are presented, for different operating points, illustrating the good control performances of the system.
\end{abstract}

Key Words - Power Control, DFIG, Wind Turbine, Variable Speed.

\section{Introduction}

For a variable-speed wind turbine the generator is controlled by power electronic equipment. There are several reasons for using variable-speed operation of wind turbines; among those are possibilities to reduce stresses of the mechanical structure, acoustic noise reduction and the possibility to control active and reactive power [1].

In this paper, we use the model developed to study and to simulate the behaviour of the DFIG connected to the grid. In a first part, we present the mechanical part of the wind turbine and the electrical part represented by the Doubly Fed Induction Generator and the ideal AC/AC Converter. The second part is devoted to the presentation of the power control algorithm, as well as the RST regulator. In order to control stator active and reactive power exchanged between the DFIG and the grid, a vectorcontrol strategy is presented. The last part deals with the study of the device using MATLAB $^{\circledR}$-SIMULINK ${ }^{\circledR}$ package. The schema of the device studied is given in the Fig.1.

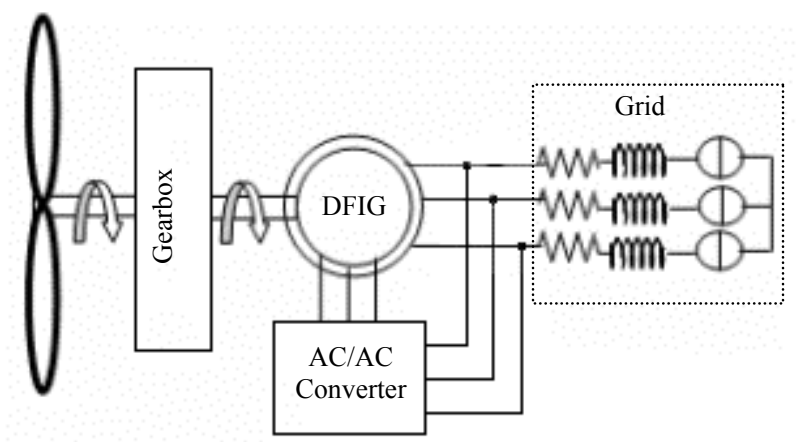

Figure1. Scheme of the studied device

\section{Turbine modelling}

The amount of power capacity of being produced by a wind turbine $P_{t}$ is dependent on the power coefficient $C_{p}$. It is given by:

$$
P_{t}=\frac{1}{2} C_{p} \rho R^{2} V^{3}
$$

Where $\rho$ is the air density, $R$ is the blade length and $V$ the wind velocity.

The turbine torque is the ratio of the output power to the shaft speed $\omega_{t}, T_{t}=\frac{P_{t}}{\omega_{t}}$.

The turbine is normally coupled to the generator shaft through a gear box whose gear ratio $G$ is chosen so as to maintain the generator shaft speed within a desired speed range. Neglecting the transmission losses, the torque and shaft speed of the wind turbine, referred to the generator side of the gearbox, are given by:

$T_{m}=\frac{T_{t}}{G}$ and $\Omega_{\text {mec }}=G . \omega_{t}$

respectively where $T_{m}$ is the driving torque of the generator and $\Omega_{\text {mec }}$ is the generator shaft speed.

A wind turbine can only generate a certain percentage of power associated with the wind. This percentage is represented by $C_{p}$ which is function of the wind speed, the turbine speed and the pith angle of specific wind turbine blades [2].

Although this equation seems simple, $C_{p}$ is dependent on the ratio $\lambda$ between the turbine angular velocity $\omega_{t}$ and the wind speed $V$.This ratio, called the tip speed ration $\lambda=\frac{\omega_{t} R}{V}$

A typical relationship between $C_{p}$ and $\lambda$ is shown in Fig.2. It is clear from this figure that there is a value of $\lambda$ for which $C_{p}$ is maximized, maximizing thus the power for a given wind speed. As depicted in Fig.3, the peak power for each wind speed occurs at the point where $C_{p}$ is maximized. To maximize the power generated, it is therefore desirable for the generator to have a power characteristic that will follow the maximum $C_{p \max }$ line. 


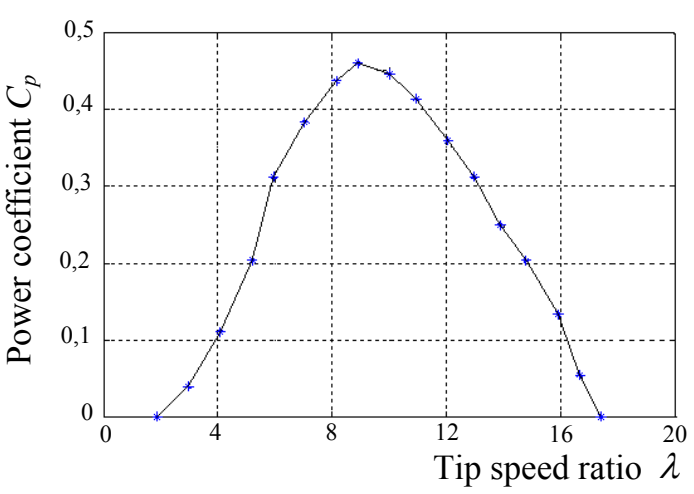

Figure 2. Power coefficient for the wind turbine model

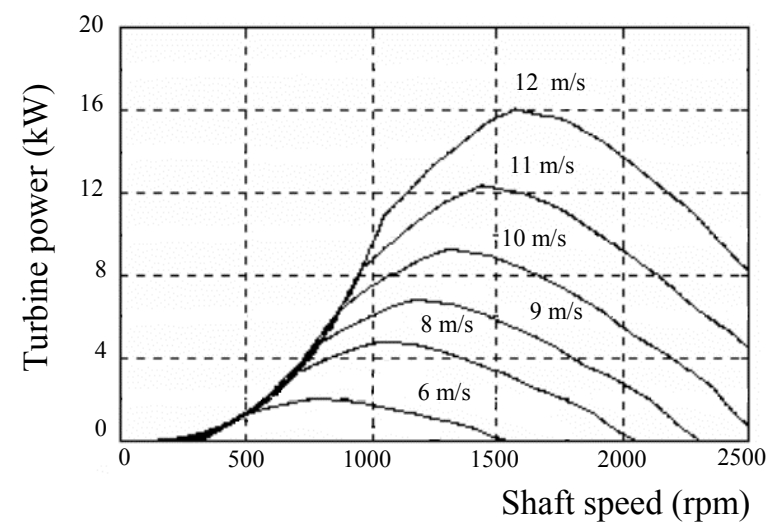

Figure 3. Power-Speed characteristics of the wind turbine

The action of the speed corrector must achieve two tasks: - It must control mechanical speed $\Omega_{\mathrm{mec}}$ with its reference $\Omega_{\text {mec ref. }}$.

- It must attenuate the action of the wind torque which constitutes an input disturbance.

The simplified representation in the form of diagram blocks is given in Fig 4.

Various technologies of correctors can be considered for the rotor speed control. We have chosen a PI regulator to carry out our model.

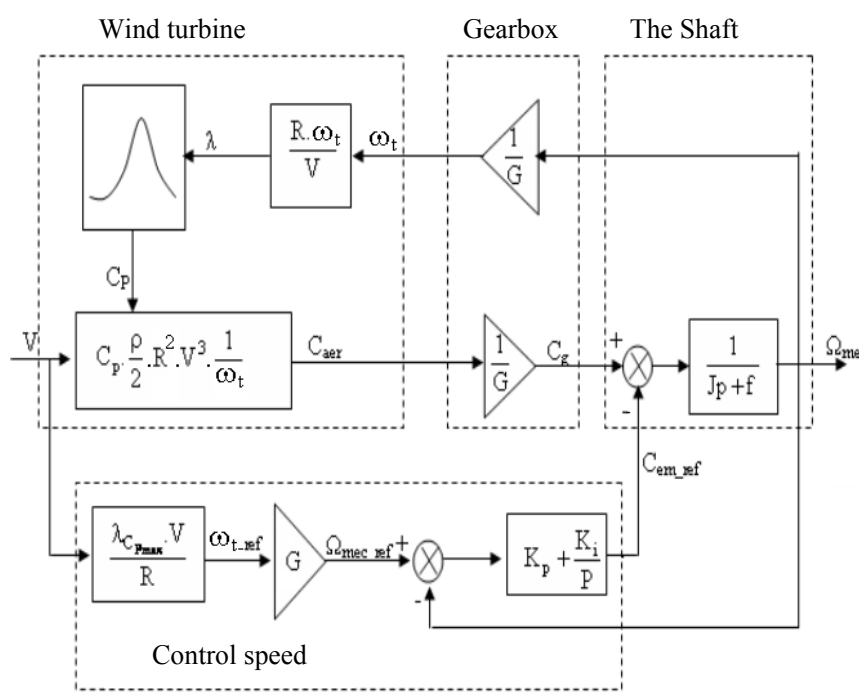

Figure4. Device control with control speed

\section{The DFIG Modelling}

The classical electrical equations of the DFIG in the Park frame are written as follows [10]:

$$
\left\{\begin{array}{l}
v_{d s}=R_{s} i_{d s}+\frac{d}{d t} \phi_{d s}-\omega_{s} \phi_{q s} \\
v_{q s}=R_{s} i_{q s}+\frac{d}{d t} \phi_{q s}+\omega_{s} \phi_{d s} \\
v_{d r}=R_{r} i_{d r}+\frac{d}{d t} \phi_{d r}-\left(\omega_{s}-\omega\right) \phi_{q r} \\
v_{q r}=R_{r} i_{q r}+\frac{d}{d t} \phi_{q r}+\left(\omega_{s}-\omega\right) \phi_{d r}
\end{array}\right.
$$

The stator flux can be expressed as:

$\left\{\begin{array}{l}\phi_{d s}=L_{s} i_{d s}+L_{m} i_{d r} \\ \phi_{q s}=L_{s} i_{q s}+L_{m} i_{q r}\end{array}\right.$

The rotor flux can be expressed as:

$\left\{\begin{array}{l}\phi_{d r}=L_{r} i_{d r}+L_{m} i_{d s} \\ \phi_{q r}=L_{r} i_{q r}+L_{m} i_{q s}\end{array}\right.$

In these equations, $R_{s}, R_{r}, L_{s}$ and $L_{r}$ are respectively the resistances and inductances of the stator and rotor windings, $L_{m}$ is the main inductance and $\omega=P . \Omega_{m e c}$ is the rotor speed.

$v_{d s}, v_{q s}, v_{d r}, v_{q r}, i_{d s}, i_{q s}, i_{d r}, i_{q r}, \phi_{d s}, \phi_{q s}, \phi_{d r}$ and $\phi_{q r}$ are

the direct and quadrate components of the space phasors of the stator and rotor voltages, currents and flux respectively.

The active and reactive powers at the stator are defined as:

$\left\{\begin{array}{l}P_{s}=v_{d s} \cdot i_{d s}+v_{q s} \cdot i_{q s} \\ Q_{s}=v_{q s} \cdot i_{d s}-v_{d s} \cdot i_{q s}\end{array}\right.$

The active and reactive powers at the rotor are defined as:

$\left\{\begin{array}{l}P_{r}=v_{d r} \cdot i_{d r}+v_{q r} \cdot i_{q r} \\ Q_{r}=v_{q r} \cdot i_{d r}-v_{d r} \cdot i_{q r}\end{array}\right.$

The electromagnetic torque is expressed as:

$C_{e m}=P .\left(\phi d s . i_{q s}-\phi_{q s} . i_{d s}\right)$

With $P$ is the number of pair poles.

\section{Active and reactive power control}

When the DFIG is connected to an existing network, this connection must be done in three steps. The first step is the regulation of the stator voltages with the network voltages as reference. The second step is the stator connection to this network. As the voltages of the two devices are synchronized, this connection can be done without problem. Once this connection is achieved, the third step, is the transit power regulation between the stator and the network (Fig.5). 


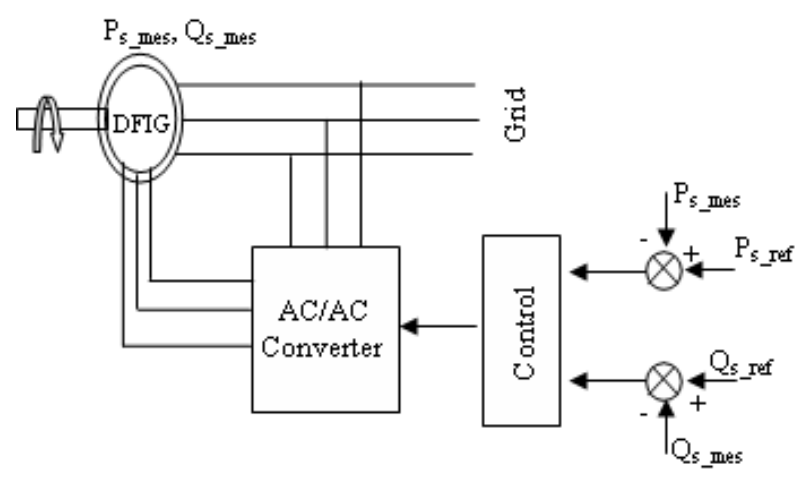

Figure5. Power control between the stator and network

To achieve a stator active and reactive power vector control as shown on Fig.5, we choose a d-q referenceframe synchronized with the stator flux [7]. By setting null the quadratic component of the stator flux:

$\phi_{d s}=\phi_{s}$ and $\phi_{q s}=0$

Then the torque is simplified into:

$$
C_{e m}=-P \frac{L_{m}}{L_{s}} I_{q r} \phi_{s}
$$

The electromagnetic torque and then the actives power will only depend on the q-axis rotor current. By neglecting the stator resistance $R_{s}$ we can write:

$v_{d s}=0$ and $v_{q s}=V_{s}$

In order to calculate angles from the Park transformation for stator and rotor variables, the stator pulsation and the mechanical speed must be sensed.

By choosing this reference frame, stator voltages and fluxes can be rewritten as following:

$$
\left\{\begin{array}{l}
v_{d s}=0 \quad ; v_{q s}=V_{s}=\omega_{s} \phi_{s} \\
\phi_{d s}=\phi_{s}=L_{s} I_{d s}+L_{m} I_{d r} ; \phi_{d r}=L_{r} I_{d r}+L_{m} I_{d s} \\
\phi_{q s}=0=L_{s} I_{q s}+L_{m} I_{q r} ; \phi_{q r}=L_{s} I_{q r}+L_{m} I_{q s}
\end{array}\right.
$$

The stator active and reactive power, can be written according to the rotoric currents as:

$$
\left\{\begin{array}{l}
P=-V_{s} \frac{L_{m}}{L_{s}} i_{q r} \\
Q=\frac{V_{s} \phi_{s}}{L_{s}}-\frac{V_{s} L_{m}}{L_{s}} i_{d r}
\end{array}\right.
$$

The rotor voltages can be written according to the rotor currents as:

$$
\left\{\begin{array}{l}
V_{d r}=R_{r} i_{d r}+\left(L_{r}-\frac{L_{m}^{2}}{L_{s}}\right) \frac{d i_{d r}}{d t}-g \omega_{s}\left(L_{r}-\frac{L_{m}^{2}}{L_{s}}\right) i_{q r} \\
V_{q r}=R_{r} i_{q r}+\left(L_{r}-\frac{L_{m}^{2}}{L_{s}}\right) \frac{d i_{q r}}{d t}+g \omega_{s}\left(L_{r}-\frac{L_{m}^{2}}{L_{s}}\right) i_{d r}+g \omega_{s} \frac{L_{m} V_{s}}{\omega_{s} L_{s}}
\end{array}\right.
$$

Where $g=\frac{\omega_{s}-\omega}{\omega_{s}}$ is defined as the generator's slip.

In steady state, the second derivative terms of both equations in (15) are nulls. The third terms, are crosscoupling terms and can be neglected because of their small influence. Knowing relation (14), it is possible to design the regulators. The global block-diagram of the controlled system is depicted on Fig. 6

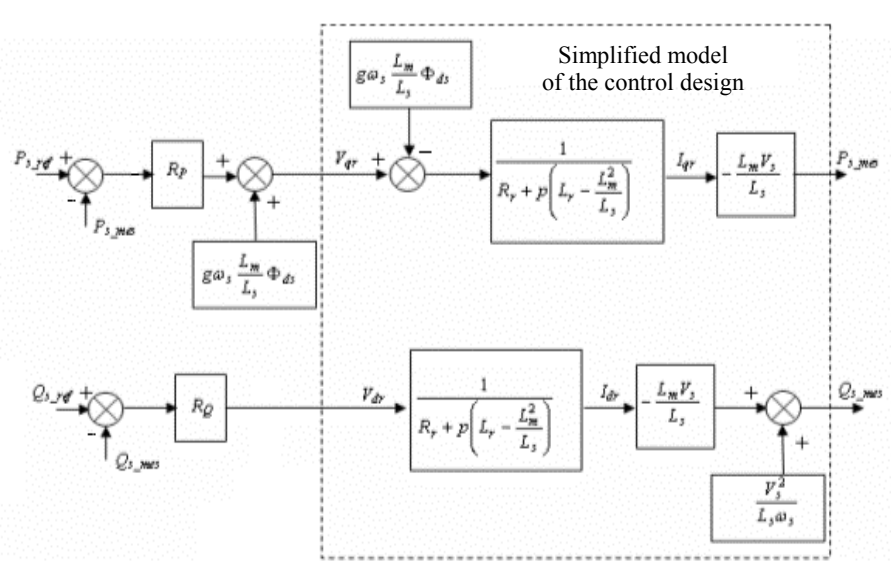

Figure 6. Block diagram of DFIG power control

\section{Results and interpretation}

We present the simulation of the DFIG connected directly to the network through the stator, and controlled by its rotor through an ideal ac/ac direct converter. To control the power exchanged between the stator and the network, one uses the vector control with direct stator flux.

The results of simulations, in the first step, are obtained with reactive power $\mathrm{Q}_{\mathrm{s} \text { ref }}=0$ and application of the echelon of active power $\mathrm{P}_{\mathrm{s}_{-} \text {ref }}=-3000 \mathrm{~W}$ at time $\mathrm{t}=2 \mathrm{~s}$ (Fig.7 to Fig.16). In the second step, we make the variation of the active and reactive references power (Fig.17 to Fig.22).

Fig.7 shows random wind turbine speed. Fig.8 shows voltage and current waveforms of the stator. Note that before the application of a level of active power the current is null whereas the voltage is equal to that of the network. When applying a level of active power with $\mathrm{t}=2 \mathrm{~s}$, a sinusoidal current, in phase opposition compared to the voltage (Fig.9), appears in the stator of the machine. The machine supplies a network with the stator active power. The sizes (stator current and voltage) are independent of the variation of the wind and depend only on the active and reactive reference powers. The DFIG slip is show in Fig.10. Fig.11 and Fig.12 show respectively active and reactive stator powers. Fig.13 shows the rotor voltage and current waveforms. The frequency of these voltage and current, vary according to the slip $\mathrm{g}$. For $\mathrm{g}=0$, the rotor voltage and current are continuous. Fig.14 gives rotor active power. It varies according to the wind speed. For $\mathrm{g}>0$, DFIG absorbs a rotor active power. For $\mathrm{g}<0$, DFIG supplies network with a rotor active power. For $g=0$, the rotor active power remained constant corresponding to the rotor joules losses. The Fig. 15 shows rotor reactive power. For $\mathrm{g}=0$, the reactive power is null. The Fig.16 shows the active 
and reactive network power. The network power varies according of the wind turbine speed. The Fig.17 and Fig.18 show respectively active and reactive powers references as well as the power available to the stator of the machine. Fig.19 and Fig.20 give respectively active and reactive rotor power waveforms. It is noticed that the powers follow their references perfectly. Fig. 21 shows voltage and current stator waveforms. If $\varphi=3 \pi / 2$, the machine works as asynchronous compensator. Fig.22 shows voltage waveform and current rotor waveforms. The DFIG operates in two quadrants. For $\mathrm{g}>0$, DFIG operates in hyper asynchronous mode. While for $\mathrm{g}<0$, DFIG operate in hypo asynchronous mode. For $\mathrm{g}=0$, DFIG operates as synchronized asynchronous generator.

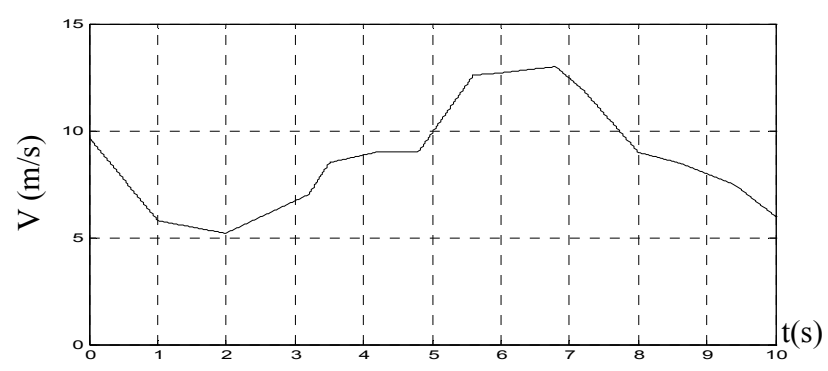

Figure7. Wind turbine speed

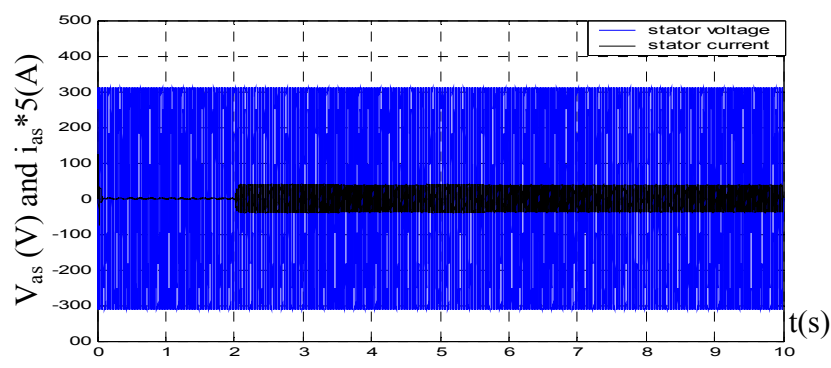

Figure8. Stator voltage and current

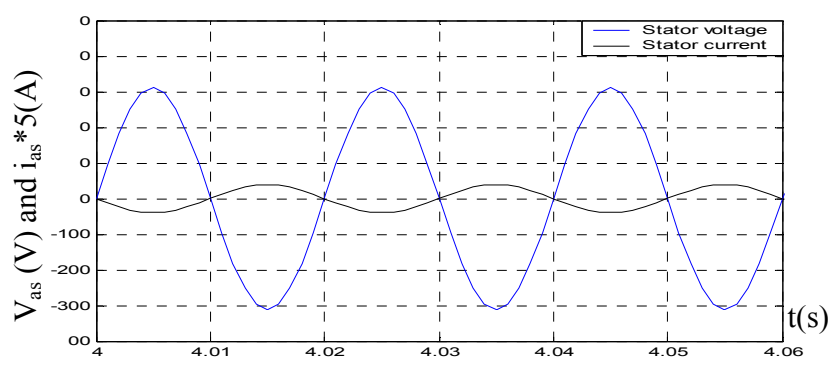

Figure9. Zoom of stator voltage and current

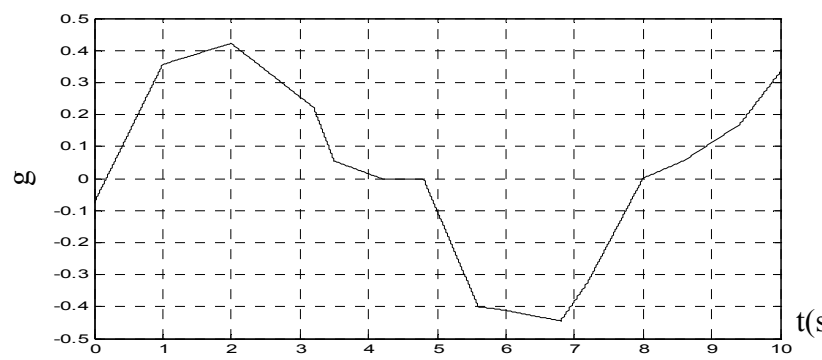

Figure10. DFIG slip g

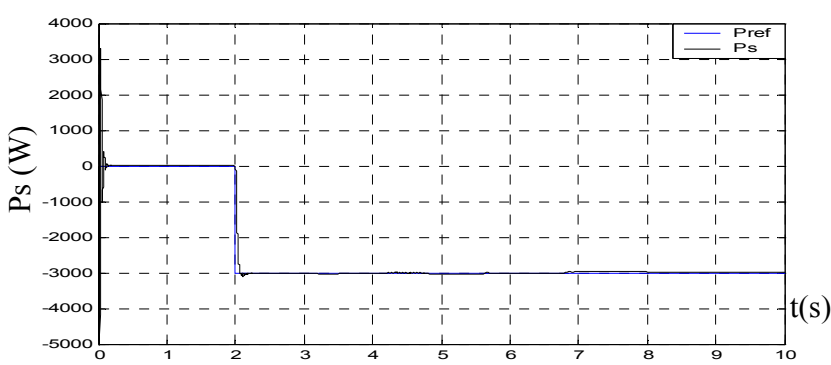

Figure11. Stator active power

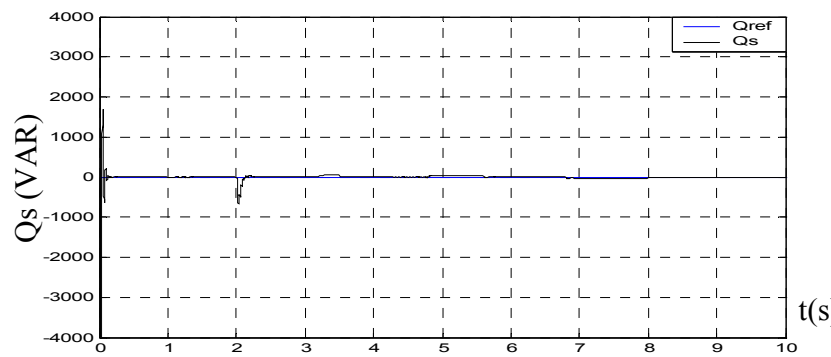

Figure 12. Stator reactive power

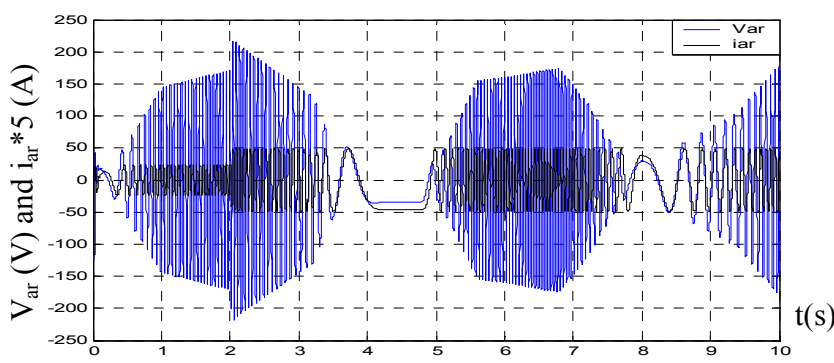

Figure13. Rotor voltage and current

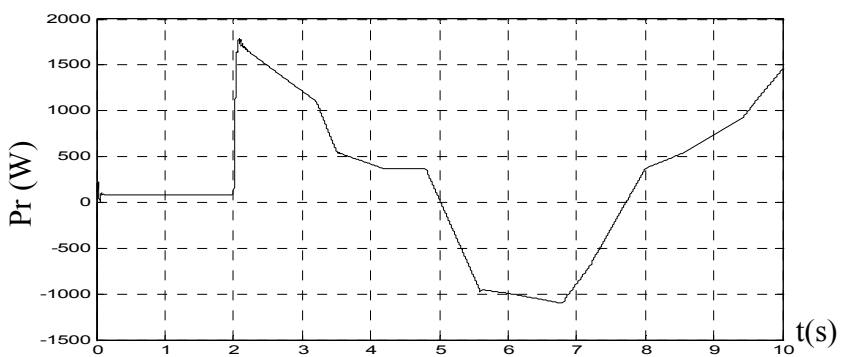

Figure14. Rotor active power

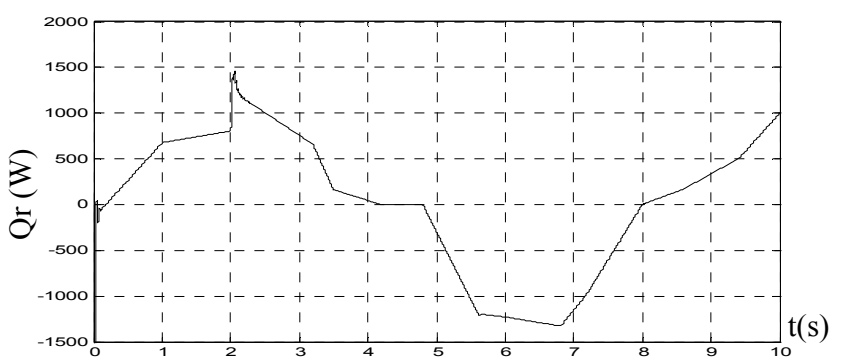

Figure15. Rotor reactive power 


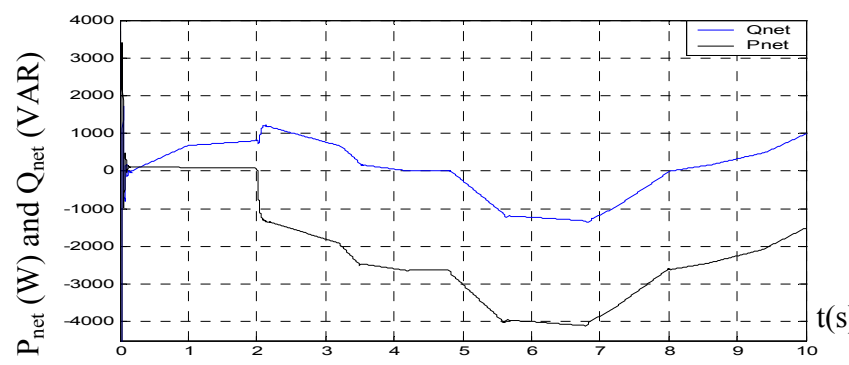

Figure16. Network active and reactive power

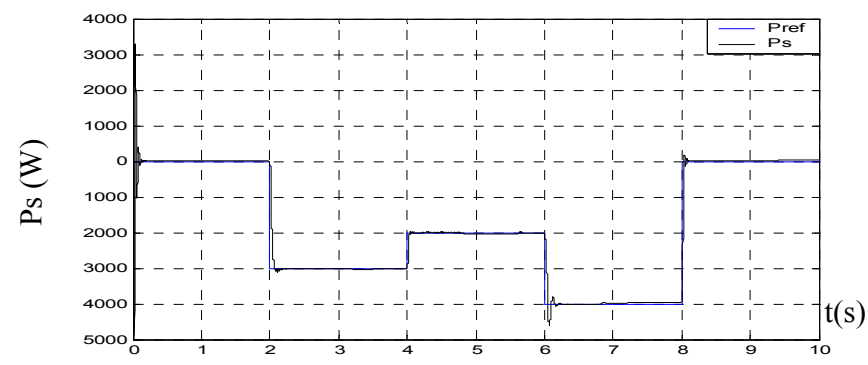

Figure17. Stator active power

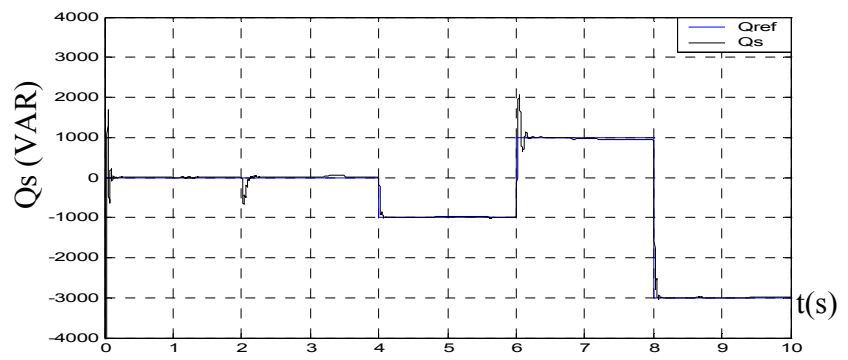

Figure18. Stator reactive power

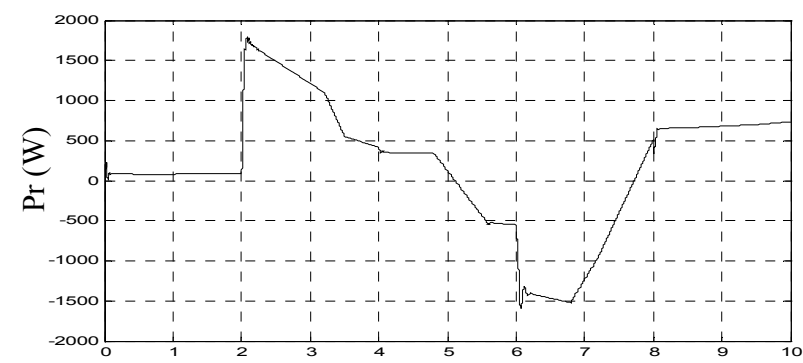

Figure19. Rotor active power

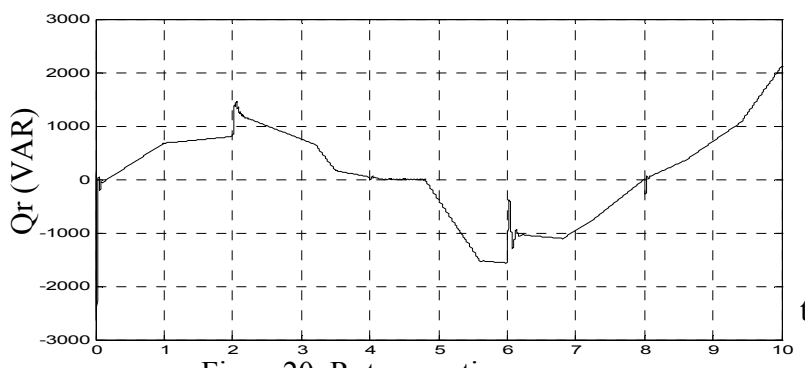

Figure20. Rotor reactive power

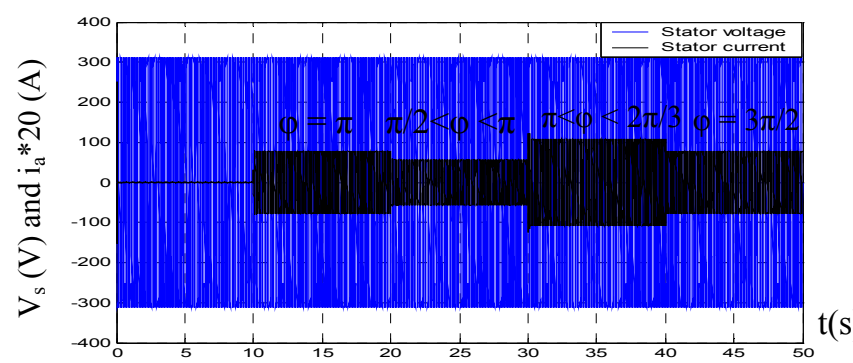

Figure21. Stator voltage and current

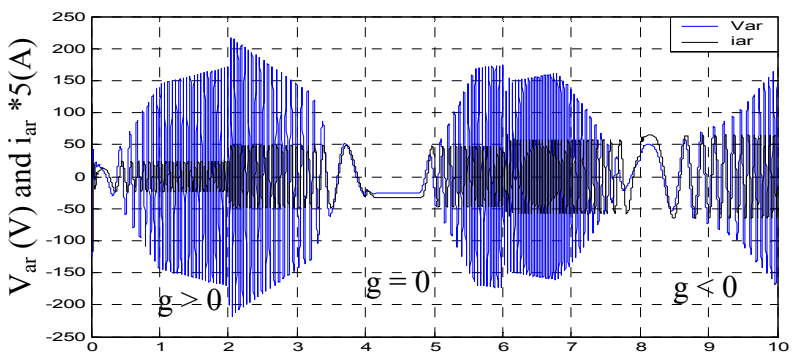

Figure22. Rotor voltage and current

\section{Conclusion}

The work presented in this paper is devoted to the analysis, modelling and simulation of a variable speed wind turbine using a doubly fed induction. Stable operation of the DFIG was achieved by means of statorflux oriented control technique. The operational principal of the proposed wind-power generator model and the validity of the control system were illustrated by the steady-state and transient responses of the power control associated to the DFIG. The DFIG operates in two quadrants. For $\mathrm{g}>0$, DFIG operates in hyper asynchronous. For $\mathrm{g}<0$, DFIG operate in hypo asynchronous model. For $\mathrm{g}=0$, DFIG operates as synchronized asynchronous generator and the rotor voltage and currents are continuous. The machine supplies network with a active power in all operating phases. Simulation results demonstrate that the proposed wind turbine generator is feasible and has many advantages.

\section{References}

[1] D. Seyoum and C. Grantham, "Terminal voltage control of a wind turbine driven isolated induction generator using stator oriented field control", IEEE transactions on industrial Applications, September 2003, pp: 846-852.

[2] L. Chang, 'Systèmes de conversion de l'énergie éolienne', IEEE Canadian Review, Summer 2002, pp: 1-5.

[3] A.Schuster, "Commande, réglage et optimisation d'un convertisseur matriciel pour entraînement par moteur asynchrone “, Doctorat Thesis L'EPLF, LEI Lausanne 1998.

[4] B. Robyns and M. Nasser, "Modélisation et simulation d'une éolienne à vitesse variable basée sur une génératrice asynchrone à cage", in the Proceeding of Electrotechnique du Futur EF'2001, Nancy, France, 14-15 Nov 2001, pp: 77-82.

[5] E. Muljadi, K. Pierce and P. Migliore, "Control strategy for variable-speed, stall-regulated wind turbines", in the Proceeding of American Controls Conference, Philadelphia, PA, 24-26 June, 1998, pp: 1-8.

[6] A. Tounzi, "Utilisation de l'énergie éolienne dans la production de l'électricité“, Journées du club EEA, 28-29 janvier 1998, Paris (France), pp 1-14. 